\title{
O DESENVOLVIMENTO DAS TECNOLOGIAS DE INFORMAÇÃO E COMUNICAÇÃO E A REORGANIZAÇÃO DO ESPAÇO UNIVERSITÁRIO
}

\author{
NITERÓI, RIO DE JANEIRO, BRASIL/RJ MAIO/2018 \\ $\begin{array}{cc}\text { Eduardo Pimentel Menezes } & \text { - PUC-RIO E UNIVERSO - epmenezes30@gmail.com } \\ \text { Adilson Tadeu Basquerote Silva } & \text { - UFSC - abasquerote@yahoo.com.br } \\ \text { Tânia Marta Costa Nhary } & \text { - UERJ - taninhary@gmail.com }\end{array}$
}

Tipo: Investigação Científica (IC)

Natureza: Planejamento de Pesquisa

Categoria: Estratégias e Políticas

Setor Educacional: EDUCAÇÃO SUPERIOR

\begin{abstract}
RESUMO
O desenvolvimento das Tecnologias da Informação e Comunicação (TIC) está promovendo novas formas de entender e vivenciar o mundo atual. É a partir desse ponto de vista que propomos, como objetivo do trabalho em tela, compreender o impacto das TIC na reorganização espacial das estruturas físicas das universidades voltadas para Educação a Distância. Para obtenção dos dados, optamos pela metodologia de análise documental (CELLARD, 2008) que permitiu a análise do processo de reorganização espacial e temporal das instituições de Ensino Superior voltadas para EAD foi o estudo do projeto CEDERJ (Centro de Educação Superior a Distância do Estado do Rio de Janeiro). Realizamos a investigação da origem do projeto, sua execução e implementação, a partir do consórcio criado em conjunto com as Universidades Públicas sediadas no Estado do Rio de Janeiro e o governo estadual. Analisamos as estruturas físicas construídas e as adaptações de estruturas espaciais voltadas para o funcionamento de cursos na modalidade a distância. Verificamos de que forma as tecnologias informacionais estão possibilitando a reorganização espacial (suas estruturas físicas) das Universidades no Brasil, a partir da possibilidade do oferecimento de cursos de graduação a distância, num claro processo de reorganização do espaço em rede. Estruturas espaciais clássicas de Campi universitário passam a conviver com estruturas descentralizadas territorialmente, com grande alcance espacial.
\end{abstract}

Palavras-chave: Espaço. Tempo. Tecnologias da informação. Educação a distância. 


\section{INTRODUÇÃO}

As noções de espaço e de tempo evoluíram através da historia, devido a vários fatores. É possível fazer uma relação entre o desenvolvimento do estado das técnicas e as transformações ocorridas com a percepção do tempo e do espaço ao longo da história da civilização ocidental.

É possível perceber, pelo menos, três momentos distintos na forma como o espaço, o tempo e a natureza são percebidos. Antes das grandes navegações (séc. XV) era a natureza que ditava os ritmos do tempo e a percepção de espaço, em função das limitadas possibilidades de se vencer as distâncias e de mecanismos técnicos que permitissem o controle da natureza. Com as grandes navegações foi possível ter um visão total do globo terrestre, modificando o sentido do espaço, que se volta para o domínio e para a conquista. Com a Revolução Industrial (séc. XVIII), o tempo necessita de um padrão mais confiável, fazendo surgir o relógio com ponteiros a ser utilizado na manufatura e, principalmente, na indústria. A partir da segunda metade do sec. XX, a transição do capitalismo industrial flexível/financeiro exige novas formas de se perceber o tempo, o espaço e a natureza, o que impulsiona o desenvolvimento das tecnologias da comunicação e da informação. O tempo real concretiza-se e o espaço virtual torna-se possível.

O surgimento da manufatura vai ser o momento de ruptura com a percepção do passado, pelo surgimento de realidades novas. A manufatura tem uma característica que vai se refletir na percepção de mundo do indivíduo comum. A manufatura não vai corresponder a uma mudança propriamente dita no estado da técnica artesanal. $O$ estado da técnica vai permanecer artesanal e a matéria-prima vai permanecer vinda do mundo vivo, mas a percepção já não será a mesma.

Há um remanejamento na arrumação da técnica artesanal que vai refletir em uma forma de percepção a partir de uma rearrumação geográfica. A arrumação da técnica artesanal, na transição para a manufatura, é uma rearrumação geográfica do estado da técnica artesanal.

A ideia de tempo que vai se construindo vai determinar uma ideia de espaço, o que significa dizer que a ideia de espaço que surge é reflexo da noção de tempo. Forma-se, assim, uma arquitetura espaço-temporal que vai encaixar-se nos elementos da natureza, arrumando a natureza de acordo com essa arquitetura e transformando a ideia de natureza. Percebe-se o início de um processo de (des)envolvimento na relação do homem com a natureza. Esse (des)envolvimento vai refletir na perda de capacidade e 
na desvalorização dos sonhos, da percepção e de uma visão de mundo apoiada no onirismo e no fantástico.

É com o Renascimento e o espaço fabril que se observa a concretização na transformação da percepção de espaço e tempo para uma dimensão racionalmatemática. A transição do artesanato para a manufatura e depois para a Revolução Industrial permite re-significar a percepção de espaço dada pela limitação das tecnologias do transporte e comunicação, como demonstra Moreira (1993): Até então, é pela tração animal ou o próprio ombro, por caminhos improvisados, que o homem vence as distâncias e supera os isolamentos. P.5. O autor chama atenção para o fato de que a Revolução Industrial desenvolve uma nova técnica que subverte os espaços em outra escala.

A Revolução Industrial introduziu a fábrica moderna na Europa, particularmente na Inglaterra. Os instrumentos de produção deixaram de ser simples ferramentas auxiliares do trabalho e passaram a realizar múltiplas tarefas que, antes, só o trabalho manual era capaz de fazer. Por isso, a "marca registrada" da Revolução Industrial foi a máquinaferramenta, que só funcionava por meio de um trabalho coletivo. Ela também torna possível uma estreita associação entre ciência e produção, permitindo que todos os processos de produção sejam estudados sem a participação do trabalhador. O volume de produção encontra-se, agora, condicionado aos limites da máquina e não mais do homem. Por isso, a Revolução Industrial significou um aumento sem precedentes na produção de mercadorias.

Ainda incluída no segundo momento, surge a Segunda Revolução Industrial, em fins do século XIX, mais precisamente em 1870 nos Estados Unidos. É a partir daí que a paisagem industrial se generaliza pelo mundo. Apesar de contar com estruturas de organização espacial e temporal baseada nas noções matemáticas e físicas, surgem alterações no ordenamento espacial comandado pela indústria. Essa nova situação se torna possível com o desenvolvimento tecnológico. A hidroeletricidade libera as indústrias de sua rígida localização das minas de ferro e carvão, interligando-se à usina termelétrica. Esse novo fator põe fim aos limites da propagação territorial da indústria. É com a Segunda Revolução Industrial que a indústria cria um metabolismo, baseado em produtos artificiais e químicos, que se contradiz ao metabolismo da natureza, dando origem aos problemas ambientais da atualidade.

Já a Terceira "Revolução Industrial", pautada na informática, microeletrônica, biotecnologia e robótica, muito associada a fase toyotista e volvista, respectivamente no final do século XX no Japão e na Suécia, reestruturam as noções de tempo e espaço. $O$ 
surgimento das infovias e infografias nos trazem a possibilidade da experiência do tempo real e do espaço virtual. Estaríamos entrando em uma nova ordem perceptiva de tempo e espaço? O espaço métrico e o tempo geométrico estariam sendo substituídos por um tempo real e o um espaço virtual? Teremos a substituição ou a coexistência e o hibridismo? Como esse novo contexto estaria influenciando nas nossas capacidades de inteligibilidade de mundo, da consciência sobre a materialidade e imaterialidade?

É o momento que se pode presenciar o surgimento de uma paisagem fracionária da instantaneidade da transferência de dados, a partir da dromosfera de Virilio (1993). Uma vertigem, um tempo real que se transmuta por entre o espaço virtual e com ele se confunde. A vertigem do tempo real e do espaço virtual, assim como a hidroeletricidade que liberou a indústria de suas rígidas localizações, libera tanto a nossa corporeidade das molduras da imobilidade territorializada que nos conferia uma espacialidade fixa, como liberou nossas mentes e imaginação para transcorrer novas formas de raciocínio e interfaces, produzindo uma nova economia do pensamento. Um pensamento mais livre, com possibilidades de uma socialidade, imerso e direcionado para as necessidades de uma sociabilidade marcada por parte das intencionalidades que direcionam o refazer de um tempo e um espaço imaterial ou sem conexões claras com as materialidades préexistentes.

\section{OBJETIVOS E REFERENCIAL TEÓRICO}

Os objetivos do trabalho em tela estruturam-se a partir da busca por compreender de que forma o desenvolvimento das tecnologias de informação e comunicação estão propiciando a reorganização espacial das estruturas físicas das Universidades que passaram a oferecer cursos de educação a distância (graduação). O estudo em tela propõe a compreensão desse impacto no a partir da criação do CEDERJ (Centro de Educação Superior do Estado do Rio de Janeiro), a partir de suas potencialidades e dificuldades de organizar outra forma de arrumação espacial para uma instituição especializada em cursos a distância. Para atingir os objetivos propostos, será apresentado um breve panorama do desenvolvimento das tecnologias associado ao surgimento de modelos de universidade a distância e, especificamente, o caso da criação do CEDERJ.

O referencial teórico utilizado encontra-se ancorado na teoria espacial de Santos (1996), na organização do espaço reticulado de Castells (1999), no advento do surgimento das universidades especializadas em cursos a distância apresentadas por Belloni (1999), nos conceitos de tecnologia estudados por Linard (1996) e na metodologia de análise documental de Cellard (2008). 


\section{PROCEDIMENTOS METODOLÓGICOS}

A metodologia utilizada foi pautada na teoria sobre análise documental de Cellard (2008), que permitiu a análise do processo de reorganização espacial e temporal das instituições de Ensino Superior voltadas para EAD foi o estudo do projeto CEDERJ (Centro de Educação Superior a Distância do Estado do Rio de Janeiro). Realizamos a investigação da origem do projeto, sua execução e implementação, a partir do consórcio criado em conjunto com as Universidades Públicas sediadas no Estado do Rio de Janeiro e o governo estadual. Analisamos as estruturas físicas construídas e as adaptações de estruturas espaciais voltadas para o funcionamento de cursos na modalidade a distância.

\section{APRESENTAÇÃO E DISCUSSÃO DOS RESULTADOS}

Cada nova forma de se perceber o tempo e o espaço está relacionada com o desenvolvimento de tecnologias que viabilizam o surgimento de diferentes percepções e de padrões culturais. A partir das afirmações proferidas, é possível perceber a efetiva relação entre tempo, espaço e tecnologia na modificação dos padrões culturais, espaciais e temporais, onde a reorganização espacial das Universidades se constitui em exemplo empírico a ser estudado.

O desenvolvimento tecnológico se constitui como referência para uma melhor compreensão de todos os aspectos de nossas vidas, inclusive da educação. Sob esse ponto de vista é possível identificar um grande número de definições sobre tecnologia. Destacamos em nosso trabalho a definição, que melhor contribui para nortear, além de ajudar a uma melhor compreensão do objetivo de nosso trabalho.

De acordo com Linard (1996), tecnologia pode ser entendida como "conjunto de discursos, práticas, valores e efeitos sociais ligados a uma técnica particular num campo particular" p.191. E prudente afirmar que existe uma grande variedade de definições sobre tecnologia. O que realmente se propõe na investigação em tela é o papel da técnica na reorganização da sociedade em todos os seus aspectos (culturais, sociais, políticos, econômicos, espaciais, temporais e sobre a natureza).

O Consórcio CEDERJ, exemplifica o processo em tela, a partir de uma organização em rede, tornando-se presente em todo o Estado do Rio de Janeiro. Pautamo-nos em autores que nos auxiliaram na interpretação desse fenômeno, como Santos (1996) e sua contribuição sobre os elementos da reorganização do espaço e do tempo associados ao fenômeno técnico e Belloni (1999) por meio de sua análise sobre o desenvolvimento da 
EAD no Brasil e no mundo. O aporte de Castells (1999) auxiliou na utilização do fenômeno contemporâneo do espaço em rede para interpretar o surgimento do Consórcio CEDERJ.

Existe uma estreita relação entre o setor produtivo e a educação superior brasileira. Para uma melhor compreensão dessa relação é necessário perceber o atual estágio de desenvolvimento econômico mundial e as demandas para a educação. Um conjunto de situações novas, como a globalização da economia, o surgimento da IV Revolução Industrial e a concorrência no mercado internacional, reivindicam novos papéis para o setor educacional. Um forte processo de modernização ocorreu no Brasil a partir dos anos 90, fazendo com que as atenções do Estado e de empresários se voltem para a educação, como forma de acelerar as mudanças do processo produtivo. Nesse cenário, Belloni (1999), destaca a expansão nas universidades do ensino EAD e identifica duas grandes categorias que agrupam uma variedade de tipos de instituição que atuam nesta modalidade. Essas duas categorias são: as instituições especializadas e instituições integradas.

As instituições especializadas encontram-se voltadas unicamente ao ensino a distância. Esse modelo é típico das universidades abertas europeias. Já as instituições integradas, são as Instituições que possuem diferentes experiências de ensino a distância, mas que se caracterizam por serem desenvolvidas em instituições convencionais, podendo estar voltadas para o ensino superior ou não. Além das duas categorias citadas, Belloni (1999) reconhece a existência de um terceiro modelo, mais recente, que se caracteriza pela organização sob a forma de rede ou consórcio. Esse modelo vem ganhando destaque, na medida em que os grandes projetos de universidades virtuais da atualidade são projetos de representação desse modelo. Como exemplo, podemos citar o CEDERJ.

O Governo do Estado do Rio de Janeiro, por meio da Secretaria de Estado de Ciência e Tecnologia (SECT), tomou a decisão de utilizar o ensino a distância para viabilizar a formação de pessoas que vêm sendo excluídas do processo educacional por questões de localização ou por indisponibilidade de tempo nos horários tradicionais de aula. Um dos aspectos que influiu nessa decisão foi a dificuldade de deslocamento de alunos do interior do Estado para as grandes cidades. Boa parte desses alunos não retorna a seus municípios de origem, o que seria desejável em razão da natural importância de uma melhor participação social no desenvolvimento das regiões do Estado. Dessa forma, o ensino a distância contribui, na medida em que permite formar profissionais sem deslocálos de seus municípios. 
Em 1999, o setor público do Estado do Rio de Janeiro ofereceu 17.591 vagas em cursos de graduação, das quais apenas 685 foram alocadas fora da região do Grande Rio. Fica claramente configurada a concentração de oportunidades no âmbito restrito dos municípios que formam a área metropolitana do Rio de Janeiro. Cerca de 322.760 candidatos prestaram vestibular em todo o Estado, no ano de 1999. Essa demanda foi crescendo, a partir da crescente procura por profissionais capacitados no mercado de trabalho. Foram justificadas medidas necessárias para oferecer à população do Estado do Rio mais um horizonte de qualificação possível.

Cabe mencionar a enorme carência de profissionais da área de educação para o Ensino Fundamental e Médio da rede pública. Nesse contexto, a Secretaria de Estado de Ciência e Tecnologia iniciou em 1999 um trabalho com o objetivo de aumentar expressivamente as oportunidades de acesso ao Ensino Superior (principalmente no interior do Estado) utilizando a educação a distância, por meio de um consórcio entre universidades públicas sediadas no Estado: Universidade do Estado do Rio de Janeiro (UERJ), Universidade do Rio de Janeiro (UNIRIO), Universidade Estadual do Norte Fluminense (UENF), Universidade Federal do Rio de Janeiro (UFRJ), Universidade Federal Fluminense (UFF) e Universidade Federal Rural do Rio de Janeiro (UFRRJ).

O Consórcio em tela produziu uma nova forma de organização "temporoespacial", se tornando um interessante objeto de pesquisa para pensar o espaço e o tempo a partir do desenvolvimento das tecnologias de informação e comunicação e consequentemente a formação de redes. Nesse sentido, Santos (1996) destaca que é possível considerar as redes como um dado social. Ao argumentar sobre o significado das redes, o autor exemplifica que as conceituações e definições se multiplicam, embora possam se enquadrar em duas matrizes de maior significação: as que consideram os seus aspectos ou sua realidade material e outra dimensão que considera também o dado social. Elas seriam um produto e uma condição social resultantes da própria sociedade nos seus mais diversos movimentos, já que fazemos parte de várias redes geográficas. $O$ importante seria pensar na conexão e na desconexão, na ausência e na presença quando as consideramos. Santos (1996) auxilia a reflexão sobre o pensar a relação entre o desenvolvimento técnico, as redes e a reorganização espacial das Universidades. A partir das considerações expostas, a ideia de campi universitário permite considerar a existência de significativas transformações nesses segmentos a partir da formação do CEDERJ.

\section{CONSIDERAÇÕES FINAIS}

Foi possível observar com a pesquisa em tela que a contemporaneidade é marcada 
pela criação e recriação de redes materiais e imateriais. Os fluxos não são animados só por formas visíveis ou audíveis, mas por dimensões imateriais, capazes de provocar a circulação. A informação não tem mais que acompanhar o corpo para se deslocar. Hoje a informação se desmaterializa, acelerando o movimento.

As redes de comunicação não deixaram de ser percebidas como mediadoras técnicas da mudança social, para se tornarem, elas mesmas, produtoras de relações sociais. Essa ideia é arriscada, já que é importante considerar que a rede não constitui o sujeito da ação. Existe uma farta literatura que defende que a rede ganha um papel de sujeito, como é possível observar em Castells (1999). Quando desconsidera os aspectos institucionais da organização dos serviços públicos que determinam, em grande medida, a morfogênese das redes. $O$ autor projeta as redes num universo de autoregulação sucumbindo ao determinismo tecnológico que ele tenta combater. É nesse aspecto que Santos (1996) nos ajuda a avançar na construção de um conceito de rede casado com o tempo presente. Ele desenvolve a ideia de que a fluidez não é uma categoria técnica e sim uma entidade sociotécnica.

Entre os objetos e lugares citados por Santos (1996) para favorecer a fluidez, acrescentaríamos as Teleuniversidades. As mesmas podem se tornar eficazes instrumentos espaciais para a difusão da informação sob a lógica das redes. O que ainda não sabemos é como e com que velocidade elas podem inserir-se em mecanismos de produção de estratégias para dinamizar a fluidificação do espaço a partir de uma lógica reticular. Nesse contexto, as empresas surgem como principal agente de inovação no sistema produtivo e, para tanto, necessitam de um novo modelo de gestão: informação, produção flexível, estrutura horizontal, áreas integradas, constante troca de informação entre os funcionários (interdisciplinaridade nas escolas), rotatividade de funções, contratação de pessoal jovem e gestão pela qualidade total. A concorrência, no contexto nacional e mundial, está mudando, de larga escala para o alto valor. Estão voltadas para o atendimento personalizado, individualizado e focalizado na necessidade momentânea do cliente, seja ele quem for, esteja onde estiver. É nesse contexto que o ensino superior a distância virtual se caracteriza como ferramenta lucrativa e eficiente do sistema econômico que vivenciamos.

É em função da fluidez e de sua constante renovação que objetos e lugares sofrem mudanças de seus valores. Essas mudanças estão em consonância com a vontade e necessidade de abolir os obstáculos à livre circulação de mercadorias, mas também a da informação. Sob esse ponto de vista, as Teleuniversidades constituem-se em importantes mecanismos espaciais de produção de uma fluidez da informação. 
O CEDERJ seria um exemplo no âmbito dessa nova dinâmica espacial reticulada, constituindo-se em um protótipo de tentativa de adaptação da forma a função. Julgamos que a forma não alcança os propósitos da função a partir do contexto que não foram projetados espaços novos. Ele utiliza as formas já existentes das Universidades conveniadas e prédios escolares em diferentes municípios. Assim, as ideias dos autores analisados e a análise do projeto, nos permite concluir que as tecnologias da informação necessitam de formas novas, que potencializem as suas novas funções ou a refuncionalização das formas existentes, fato não evidenciado no consórcio CEDERJ.

Cabe dizer, que há a necessidade de adensar os estudos e análises do projeto CEDERJ sob a perspectiva aqui apresentada. Contudo, inferimos que as Teleuniversidades ainda não conseguiram atingir um padrão espacial adequado às necessidades da fluidez da informação no contexto da economia de mercado globalizada. Os mecanismos tecnológicos não conseguiram, ainda, adequarem-se às próteses espaciais já existentes e a necessidade da construção de novas próteses espaciais, construídas para adequar a tecnologia informacional à função de uma universidade.

\section{REFERÊNCIAS}

BELLONI, Maria Luíza. Educação a Distância. Rio de Janeiro: Autores Associados. 1999.

CASTELLS, Manuel. A Sociedade em Rede. São Paulo: Paz e Terra, 1999.

CELLARD, André. A análise documental. In: POUPART, J. et al. A pesquisa qualitativa:enfoques epistemológicos e metodológicos. Petrópolis, Vozes, 2008.

LINARD, M. Des Machines et des Hommes. Paris: L Harmattan, 1996.

MOREIRA, R. O Círculo e a Espiral. Rio de Janeiro: obra aberta, 1993.

SANTOS, Milton. A Natureza do Espaço (técnica e tempo, razão e emoção). São Paulo: Hucitec, 1996.

VIRILIO, P. O Espaço Crítico. Rio de Janeiro: Editora 34, 1993. 